\title{
Physical Activity at Moderate and High Altitudes. Cardiovascular and Respiratory Morbidit
}

\author{
Augusta L. Campos, Ricardo Vivacqua C. Costa
}

Rio de Janeiro, RJ - Brazil

In recent decades, sports activities related to nature have become increasingly popular. As more and more people look for ski resorts in mountainous regions or become involved with activities such as walking and/or mountain climbing at moderate and high altitudes, diseases related to this environmental stress become problems that doctors have to face with an increasing frequency; they need, therefore, to know these entities better. In addition, many athletic competitions are performed at altitudes above 2,000 m, such as the Olympic Games of 1968 and the World Cup Soccer Games of 1970, which took place in Mexico City, Mexico, at 2,240 m. Experts have been investigating how to improve athletic performance in such situations.

"Diseases of altitude" are primarily caused by hypoxia and are influenced by the cold weather and the time of exposure. The main syndromes are acute mountain sickness (AMS), high-altitude pulmonary edema (HAPE), and high-altitude cerebral edema (HACE). Potential noxious effects of the hypobaric hypoxia include conditions such as coronary heart disease, pulmonary diseases, hemoglobinopathies and pregnancy.

\section{Acute responses to hypobaric hypoxia}

Cardiopulmonary effects-systemic blood pressure: In normotensive individuals, the results of the studies regarding the response of blood pressure (BP) to initial exposure to hypobaric hypoxia have been distinct. Some investigators have found an increase in $\mathrm{BP}^{1-5}$, others a slight reduction ${ }^{6-7}$, and others no change at all ${ }^{8,9}$. The tendency observed in most of the studies, however, is an increase in blood pressure levels on the first day of exposure to a significant altitude and, later, a decline of the values to those found at sea level, mainly in regard to the systolic blood pressure (SBP) ${ }^{3,5}$.

Studies evaluating the behavior of pressure in normotensive individuals during exercise, after acute exposure to hypobaric hypoxia, have also shown discrepancies. Balke ${ }^{10}$

Hospital Pró-Cardíaco - Rio de Janeiro - Brazil

Mailing address: Ricardo Vivacqua - Lab. de Medicina do Exercício do Hospital Pró-Cardíaco - Rua Dona Mariana, 219 - 22280-020 - Rio de Janeiro, RJ - Brazil observed an increase of 5 to $10 \mathrm{mmHg}$ in the SBP and a reduction of $5 \mathrm{mmHg}$ in diastolic BP in 6 individuals during exercise on a bicycle at a simulated altitude of $4,200 \mathrm{~m}$, when compared with that found at sea level. Malconian et al ${ }^{11}$ found a $10 \%$ reduction in the mean $\mathrm{BP}$ at maximal effort, in a simulated altitude of $8,848 \mathrm{~m}$, corresponding to the summit of Mount Everest, compared with the values found at sea level. D'Este et al ${ }^{12}$ performed a submaximal test on 10 normotensive individuals after acute exposure to $2,500 \mathrm{~m}$ and did not find significant differences in the pressure response compared with the results of the test at sea level. Palatini et al ${ }^{13}$ found a significant increase in the SBP at rest but not at the maximal effort, in 5 endurance athletes, who underwent a prolonged submaximal test on bicycles, 12 hours after exposure to $3,322 \mathrm{~m}$.

In regard to investigations in hypertensive patients, D'Este et al ${ }^{12}$ did not observe any change in $\mathrm{BP}$ at rest, but SBP significantly increased to the submaximal level during exercise, but not at the maximal effort. Savonitto et a ${ }^{14}$ studied the effects of acute exposure at $3,460 \mathrm{~m}$ on the response of BP to dynamic and isometric exercises in 11 men with light to moderate systemic hypertension. The results observed were light increases in the SBP at rest but no significant changes occurred during the exercise. In the handgrip test, $\mathrm{BP}$ and heart rate (HR) were not influenced by the acute exposure to the hypobaric hypoxia.

We understand that the diversity of the methodologies of the different experiments has rendered the comparison of the results difficult.

The small number of hypertensive individuals studied under these conditions and the wide variety of responses among them do not allow us to exclude the possibility that nontreated hypertensive individuals, when exercising at moderate and elevated altitudes, may have pressure levels hazardously elevated.

Cardiovascular autonomic modulation - Sympathetic nervous activity increases with the increase in altitude, but it relates better to the ventilatory response to chronic hypobaric hypoxia than to the severity of the hypoxia itself ${ }^{15}$.

Acute exposure to hypobaric hypoxia increases HR at rest ${ }^{2-5,11}$. It also increases the component of low frequency and reduces that of high frequency in the spectral analysis ${ }^{3,8}$. 
The maximal HR of the exercise, however, may be maintained or undergo reduction ${ }^{11,14,16}$. The last behavior is more prevalent at high altitudes ${ }^{11}$, maybe because of the longer time of exposure to hypoxia inherent in those conditions. Malconian et al $^{11}$ found a $25 \%$ reduction in the maximal $H R$ at a simulated altitude of $8,848 \mathrm{~m}$, in relation to that at sea level. Savard et al ${ }^{16}$ observed a partial restoration of the previous levels in individuals who had been at altitudes between 5,250 and $8,700 \mathrm{~m}$, after inhalation of $60 \% \mathrm{O}_{2}$.

Sagawa et al ${ }^{17}$ examined the baroreflex response of 7 nonacclimatized men at sea level and at the first hour of exposure to altitudes between 3,800 and 4,300m, in a hypobaric chamber. The results were in accordance with a significant reduction $(\mathrm{p}<0.05)$ in the sensitivity of the carotid baroreflex cardiac response.

These results suggest that the acute response to the hypobaric hypoxia relate more to an increase in the sympathetic activity. A longer exposure to this environmental condition causes a reduction in the adrenergic activity ${ }^{16}$. Chronic hypobaric hypoxia may reduce the maximal HR by reducing the density and affinity of the beta-adrenergic receptors, as already demonstrated for the alpha- 2 receptors ${ }^{18}$.

Pulmonary ventilation and saturation of oxygenBarometric pressure decreases as altitude increases. While the percentage of oxygen in the air remains constant $(20.93 \%)$, the partial pressure of oxygen decreases ${ }^{19}$. The lower density of the air at high altitudes reduces the resistance of the airways, and the maximal inspiratory and expiratory flows are higher than at sea level ${ }^{20}$. In spite of this, however, the efficacy of the ventilatory muscles may be reduced due to hypoxia, and therefore, be a limiting factor to exercise ${ }^{20}$.

Pulmonary ventilation increases and, inversely, saturation of oxygen $\left(\mathrm{SaO}_{2}\right)$ drops with an increase in altitude $e^{2,5,20}$.

Malconian et $\mathrm{al}^{21}$ studied 8 healthy men (age range: 21-31 years) in simulated altitude (hypobaric chamber) during the sleeping period. $\mathrm{SaO}_{2}$ at sea level was $97 \pm 1 \%$, at $4,572 \mathrm{~m}$ it was $79 \pm 3 \%$, at $6,100 \mathrm{~m}$ it was $62 \pm 11 \%$, and at $7,620 \mathrm{~m}$ it was $52 \pm 2 \%$. During maximal exercise at $8,848 \mathrm{~m}$ in a cycloergometer, the mean $\mathrm{SaO}_{2}$ reached $49 \%$ with a mean $\mathrm{pH}$ of $8{ }^{11}$.

Oxygen uptake $\left(\mathrm{VO}_{2}\right)$ - Several studies show a reduction in $\mathrm{VO}_{2}$ at rest and/or at certain level of exercise at moderate and high altitudes ${ }^{5,22,23}$.

Basu et al $^{5}$ studied 16 men (age range: 20 -30 years) during the initial days of acclimatization in the Himalayas, at altitudes between 3,100 and 4,200m. The values of $\mathrm{VO}_{2}$ at rest and during submaximal exercise with a load of $100 \mathrm{~W}$, at sea level, were, respectively, 3.25 and $20.31 \mathrm{~mL} / \mathrm{kg} / \mathrm{min}$. At the altitude of $3,110 \mathrm{~m}$, the values of $\mathrm{VO}_{2}$ at rest and during the submaximal effort with $100 \mathrm{~W}$ dropped significantly $(\mathrm{p}<0.001)$ and continued to $\operatorname{drop}(\mathrm{p}<0.01)$ at $4,177 \mathrm{~m}$.

At lower altitudes, $2,500 \mathrm{~m}$, Levine et $\mathrm{al}^{23}$ observed a $12 \%$ reduction of the peak $\mathrm{VO}_{2}$ in a population of 20 old people, during the acute exposure; $\mathrm{VO}_{2}$ reached normal values after acclimatization. In another extremity, at the simulated altitude of Mount Everest, an $80 \%$ drop in the maximal $\mathrm{VO}_{2}$ in relation to sea level was found ${ }^{24}$.

Pressure of the pulmonary artery and ventricular function - Davila-Roman et $\mathrm{al}^{25}$ studied the ventricular function in 14 runners who had completed an ultramarathon at high altitude (2,350 to 4,300m's), to evaluate if prolonged exercise, such as in this type of race, would damage the left ventricle $(\mathrm{LV})$. Until then, there were reports of damage to the LV after strenuous exercise. Before the race, the echocardiograms were normal; SBP of the pulmonary artery had a mean value of $28 \mathrm{mmHg}$ and the dosages of troponin I was undetectable. Immediately after the marathon, the echocardiograms showed, as expected, global and segmental increase of the left ventricular function in all individuals and, except for one, the values of troponin I were undetectable. However, in 5 of them, marked dilation with hypokinesia of the right ventricle (RV) was observed, as well as paradoxical movement of the interventricular septum, pulmonary hypertension, and bronchospasm. One of these individuals showed a slight elevation of troponin I. At the end of one day; these findings had already normalized. Therefore, in this sample of athletes performing at high altitudes, inversely to the expectation, the ventricular damage occurred in the RV and not in the LV. The incidence and pathogenesis of these findings still need to be determined. We do not think that the RV impairment is exclusively secondary to the ultramarathon.

Malconian et al $^{11}$ found electrocardiographic alterations compatible with pulmonary hypertension (increase in the amplitude of the $\mathrm{P}$ wave in $\mathrm{D}_{2}, \mathrm{D}_{3}, \mathrm{AVF}$, right shift of the $\mathrm{QRS}$ axis, increase in the ratio $\mathrm{S} / \mathrm{R}$ in the left precordials and increase in the negativity of the $\mathrm{T}$ wave in $\mathrm{V}_{1}$ and $\mathrm{V}_{2}$ ), from the simulated altitude of $6,100 \mathrm{~m}$ on. Most of the changes reversed to normal 12 hours after the return to sea level.

Respiratory changes and arrhythmias during sleepAt high altitudes and during sleep, some healthy individuals have a periodical respiratory pattern, also called CheyneStokes respiration ${ }^{17,21,26}$. Combined with this variation, there are cyclic changes in the cardiac rhythm and HR ${ }^{19}$. Cummings and Lysgaard ${ }^{27}$ recorded their own cardiac rhythms and observed a pronounced respiratory sinus arrhythmia and bradycardia during sleep at 5,033m.

During the Operation Everest II, simultaneous records of respiration and electrocardiogram were performed in 8 individuals during sleep ${ }^{21}$. The evaluations were carried out at sea level and at the following altitudes: 5,490m, 6,100m, and $7,620 \mathrm{~m}$. The results found at high altitudes were the following: sinus bradycardia $(41 \pm 0.5 \mathrm{bpm})$, bradycardiatachycardia cycles respectively related to the phases of the periodical respiratory cycle of bradypnea/apnea and tachypnea, sinus arrhythmia, junctional escapes, and ventricular and supraventricular extrasystoles. Similar results had already been observed in previous studies ${ }^{21}$.

The mechanisms of these alterations of respiration and cardiac rhythm are yet to be determined. Administra- 
tion of oxygen or carbon dioxide eliminates apnea but not the respiratory periodicity during exposure to hypobaric hypoxia ${ }^{19}$. A mechanism of vagal modulation may be involved $^{21}$.

Endocrine alterations - Roberts et al ${ }^{28}$ observed an increase in glucose cellular uptake, at rest and during submaximal exercise, resulting from exposure to hypobaric hypoxia. According to these authors, glucose utilization is higher initially than after acclimatization, and this is intensified by the use of beta-blockers. McClelland et $\mathrm{al}^{29}$, studying rats, did not find any increase in carbohydrate utilization.

Hypobaric hypoxia increases diuresis. During the Australian Bicentennial Mount Everest Expedition ${ }^{30}, 10$ individuals were evaluated in regard to the effects of the exposure to an altitude of 5,400m on the plasmatic concentration of the atrial natriuretic peptide. Results showed reduction in the activity of plasmatic renin and aldosterone, increase in the levels of the atrial natriuretic peptide, and also increase in the diuresis and natriuresis.

Zaccaria et al $^{31}$ studied the hormones that regulate sodium in 7 men, one week and 21 days after being at $5,050 \mathrm{~m}$, before and after exercise and they compared the results to those obtained at sea level. Plasmatic samples of renin, aldosterone and atrial natriuretic peptide activity were obtained at the orthostatic position and at the end of a maximal exercise. Sodium excretion and the urinary volume in 24 hours were also evaluated, as well as the total body water and hematocrit. They found a constant suppression of the plasmatic renin activity and of the aldosterone levels, the opposite of the findings at sea level, concluding that these hormones were not stimulated by strenuous exercise. They also observed an increase of the atrial natriuretic peptide during acute exposure, but not during chronic exposure.

We consider the above-discussed endocrine alterations not yet well clarified, requiring further studies.

Endothelial and blood alterations - Endothelin 1: Exposure to a continuous increase in altitude progressively increases plasmatic endothelin 1 (ET-1) ${ }^{32,33}$, which is a peptide synthesized by endothelial cells, with potent vasoconstrictive and mitogenic action upon the vascular smooth muscles.

Morganti et al ${ }^{32}$ observed changes in the plasmatic dosages of ET-1 (from $1.8 \pm 0.1 \mathrm{pg} / \mathrm{mL}$, at sea level, to $2.7 \pm$ $0.2 \mathrm{mg} / \mathrm{mL}$, at $4,240 \mathrm{~m})$, concomitantly with reductions of the $\mathrm{SaO}_{2}$ (from $98.6 \pm 0.2 \%$, at sea level, to $80.8 \pm 0.4 \%$, at that altitude). In a study of 6 men climbing the Monte Rosa in the Alps $(4,559 \mathrm{~m})$, those authors also found increases in the pulmonary SBP(from $19 \pm 1$ to $26 \pm 1.9 \mathrm{mmHg}$ ), directly related to the increase of plasmatic ET-1.

Increase in the plasmatic ET-1 has been observed in cases of HAPE (high-altitude pulmonary edema), including in the bronchoalveolar lavage, and it is part of one of the hypotheses about the pathogenesis of HAPE ${ }^{33}$.

Erythropoietin - A few hours after exposure to hypobaric hypoxia, the secretion of renal erythropoietin increa- ses ${ }^{34-37}$. As it stimulates the synthesis of red blood cells, in approximately one week it significantly increases the concentration of hemoglobin and, therefore, the capacity of transporting $\mathrm{O}_{2}$ in the blood ${ }^{38}$. Therefore, even though erythropoietin levels increase at the acute phase of exposure to higher altitudes, its effects will be felt during acclimatization.

Vascular endothelial growth factor - Asano et at ${ }^{37}$ studied 8 swimmers training at $1,886 \mathrm{~m}$. After 10 days of training, they observed transient reduction in the levels of the vascular endothelial growth factor (VEGF) in the serum, followed by a significant increase, reaching a peak at the $19^{\text {th }}$ day. The initial values were obtained one month after the return to a low altitude. We do not know, however, if the reduction of VEGF occurred in the first days of exposure to altitude.

\section{Acclimatization}

Hypobaric hypoxia triggers adaptive physiological mechanisms destined to satisfy the energetic needs of the cells. Acclimatization happens when after days of exposure to a certain altitude, usually a period of 2 to 3 weeks, there is a chronic adaptation to environmental conditions ${ }^{38,39}$.

The physiological mechanisms are the following: 1) increase in the pulmonary ventilation ${ }^{39} ; 2$ ) reduction in the HR previously increased in the acute response ${ }^{22,39}$; 3) decrease in the plasmatic volume $\left.{ }^{39,40} ; 4\right)$ reduction of the accumulation of lactate in the blood during submaximal exercise in relation to the more elevated levels of acute response ${ }^{39}$; 5) improvement of the cardiorespiratory capacity for exercise, also related to the initial exposure to the hypobaric hypoxia $^{23,41} ; 6$ ) increase in the secretion of renal erythropoietin, in the hemoglobin mass and in the hematocrit ${ }^{34,36,37,42}$.

The time necessary for each of these responses varies. Some of them are fully manifested within days of arrival at a certain altitude, while others may require 2 to 3 weeks ${ }^{39}$. In regard to extreme altitudes, such as those above $8,000 \mathrm{~m}$, however, a period of 77 days seems to be more adequate ${ }^{43}$.

Unlike the acclimatization period, the return to the biological conditions at sea level is much less known. Beidleman et al ${ }^{39}$ studied the effects of acclimatization on 6 men who, after 16 days at $4,300 \mathrm{~m}$, stayed for 8 days at sea level, returning then to the previous altitude, but at this time in a hypobaric chamber. Even though the performance of the submaximal exercise was not maintained after the return to the altitude, several responses of acclimatization were retained. These responses lasted longer than necessary for acclimatization, except for the HR; this fact may be explained by the rapid changes of the autonomous nervous system. Some individuals, whose work is athletic competition or recreational activities involving intermittent journeys into high altitudes, may benefit from the responses to previous acclimatization.

\section{Diseases of altitude}

Even though acute mountain sickness (AMS), high- 
altitude pulmonary edema (HAPE) and high-altitude cerebral edema (HACE) are distinct disorders, they relate to each other. They usually occur in young and healthy people as a result of poor acclimatization. The more severe forms of HAPE and HACE are not necessarily preceded by MAS ${ }^{26}$.

Acute mountain sickness (AMS) - AMS is the most common of all. It is usually self-limited and rarely leads to death. Symptoms appear between 4 and 8 hours after arrival at the altitude ${ }^{35}$, and the most characteristic ones are the following: headache, nausea, insomnia, anorexia, and dyspnea ${ }^{17,26,38}$. Despite the individual tolerance to hypobaric hypoxia, the best way to prevent AMS is to ascend slowly 19,26,38,44. One should also avoid strenuous efforts at the initial phase of acclimatization, provide a good hydration ingesting at least 3 liters of water per day, and eat light meals in which carbohydrates predominate ${ }^{19,26}$. In all 3 situations, the best treatment is the descent ${ }^{19,26,44,45}$.

Controlled studies have shown that acetazolamide reduces the incidence and severity of MAS ${ }^{17,46,47}$. Being an inhibitor of carbonic anhydrase, it facilitates the excretion of urinary bicarbonate, promoting reduction of the respiratory alkalosis and, therefore, increasing the respiratory drive with reduction of the nocturnal hypoxemia ${ }^{19,26,38,47}$. Doses used vary from 125 to $250 \mathrm{mg}$ every 12 hours or $500 \mathrm{mg}$ in tablets with prolonged release every 24 hours. Drug intake should start one day before ascent and continue until 2 days after reaching the maximal height or can be maintained for longer periods, if the risk of AMS is high ${ }^{19,26,38,47}$. The side effects can include increase in diuresis, epigastralgia, and paresthesia ${ }^{19,26,46,47}$.

High-altitude pulmonary edema (HAPE)-HAPE is a noncardiogenic pulmonary edema. It is accompanied by pulmonary hypertension, an increase in the pulmonary capillary permeability and hypoxemia ${ }^{48}$. HAPE typically occurs in young and healthy mountaineers and is precipitated by rapid ascents at altitudes above $2,500-3,000 \mathrm{~m}^{45,48-50}$. There is an individual susceptibility and it tends to recur 45,48,49,51 . HAPE clinically manifests 2 to 5 days after acute exposure to hypobaric hypoxia, $78 \%$ of the cases appear until the $10^{\text {th }}$ day ${ }^{38,45}$, with the following symptoms: abnormal dyspnea on effort and, later, even at rest, cyanosis, dry cough that evolves to a mucous-sanguinolent cough, and tachycardia ${ }^{19,38}$. Teleradiography shows diffuse alveolar images unevenly distributed ${ }^{19,38,45}$. The alveolar fluid is rich in proteins and inflammatory mediators ${ }^{33,45,52,53}$.

HAPE is a severe and potentially fatal condition and immediate descent is mandatory ${ }^{19,26}$. If this is impossible or concomitantly with the descent, the therapeutical scheme recommended is to inhale oxygen and use $10-20 \mathrm{mg}$ of nifedipine by sublingual via plus $20 \mathrm{mg}$ of slow-release nifedipine, which should be repeated every 6 hours ${ }^{26,38,53,54}$.

In a double-blind study, the prophylactic use of nifedipine reduced the incidence of recurrent pulmonary edema in mountaineers during ascent at $4,559 \mathrm{~m}^{55}$. This calcium channel antagonist decreases the pulmonary artery pressu- re and increases $\mathrm{SaO}_{2}$. A blocking action of the inflammatory response to hypoxia was also described ${ }^{54}$.

Inhalation of nitric oxide has been recently tried in the treatment of HAPE, because of its selective vasodilating action upon the pulmonary vascular network ${ }^{56}$. Anand et al ${ }^{56}$ treated random patients with moderate to high intensity $\mathrm{HAPE}$ with $50 \% \mathrm{O}_{2}$, nitric oxide at $15 \mathrm{ppm}$, a mixture of $\mathrm{O}_{2}$ and nitric oxide, and environmental air. They discovered that both $\mathrm{O}_{2}$ and nitric oxide reduce the pressure in the pulmonary artery and also the pulmonary perfusion-ventilation disorder, and improve oxygenation. The results showed an additive effect with a more significant improvement of the pulmonary hemodynamics and of the gas exchanges, when $\mathrm{O}_{2}$ and nitric oxide are simultaneously used.

Pathophysiology of HAPE remains partially unknown. Accumulation of fluid with a high content of protein in the alveolar space results from an increase in the permeability of the pulmonary vascular endothelium, exceeding the capacity of reabsorption ${ }^{53}$. There are several hypotheses to explain this increase in permeability and some of them are listed below: 1) pulmonary arterial hypertension ${ }^{57-59}$;2) hypoxia inducing the release of inflammatory mediators, such as cytokines, ET-1, and intercellular adhesion molecule (ICAM-1) ${ }^{33,52}$; 3) hyperperfusion of the pulmonary vessels not undergoing vasoconstriction (hypoxic pulmonary vasoconstriction is extensive but not uniform) leading to dilation and high flow in the capillaries and consequent capillary lesion ${ }^{60}$. On the other hand, the rapid normalization that occurs with oxygen therapy and descent indicates a preserved pulmonary "architecture" ${ }^{53}$. Perhaps the interaction of these and other hypotheses may explain the mechanisms responsible for $\mathrm{HAPE}$.

A study trying to elucidate the reason for a constitutional predisposition to recurrent HAPE was recently published. Hanaoka et $\mathrm{al}^{49}$ showed that some human lymphocyte antigens (HLA) are increased in Japanese patients with HAPE, especially those with the recurrent disease. HLA-DR6 and/or HLA-DR4 were most frequently found in Japanese individuals with HAPE than in a control group. The HLA-DR6-positive individuals with HAPE had significantly higher pulmonary arterial pressures than other HLADR6-negative patients with HAPE. The authors say that at least some cases of HAPE are immunologically mediated, perhaps through a greater susceptibility to pulmonary hypertension. This study supports the observations of Steinacker et al ${ }^{61}$, who found a smaller pulmonary vasoconstriction, a greater vascular capacitance and a greater ventilatory response during exercise in individuals resistant to HAPE compared with those who had HAPE.

High-altitude cerebral edema (HACE) - It usually happens at altitudes higher than $4,500 \mathrm{~m}^{38}$. Intense headache, mental confusion, hallucinations, and ataxia ${ }^{19,38}$ characterize HACE. The victim is usually tired, with no conditions to objectively evaluate his/her own status, may have hallucinations and walk like a drunken person ${ }^{19}$. The fine movements of the hands, fingers and eyes are affected ${ }^{19}$. Edema 
and petechial hemorrhages are typically found in the brain at autopsy ${ }^{19}$. Prevention can be done through a slow ascent, good hydration and avoidance of strenuous exercises ${ }^{19,26}$. Descent is the treatment and it should be started immediately because evolution to death can be rapid ${ }^{19,26,38}$. Oxygen improves the symptoms, but when interrupted, the situation aggravates even more ${ }^{19}$. Dexamethasone does not affect cerebral edema, but reduces the symptoms and, therefore, makes the descent easier ${ }^{26}$.

\section{Sports activities at moderate and high altitudes}

There are 3 groups of individuals classified according to their way of responding to hypobaric hypoxia. The groups are the following: 1) healthy people living at sea level or at low altitudes; 2) those who were born and live at moderate and high altitudes; 3 ) those with heart diseases, pulmonary diseases and hemoglobinopathies.

The first group can be subdivided into sedentary, active and athletic individuals. The acclimatization process has no direct correlation with the previous level of physical conditioning. An athlete with high aerobic conditioning is equally exposed to the diseases of altitude as a sedentary individual. In absolute values, however, especially after the acclimatization period, the differences in the cardiopulmonary capacities are kept as at sea level. Physical training and the intensity of the exercises should be differentiated and adequate to each subgroup.

The second group is well represented by the Sherpas, a small ethnic group living in the Himalayas at altitudes ranging from 3,000 to $4,900 \mathrm{~m}^{62}$. The maximum altitude a man can permanently live at is $5,300 \mathrm{~m}^{63}$. A large number of those people provide support to climbers of the highest mountains in the world, as carriers and mountain guides, and they usually do this without an extra oxygen supply.

Garrido et al $^{62}$ assessed the cardiorespiratory capacity of 6 Sherpa climbers at sea level. They found a $\mathrm{VO}_{2}$ max of $66.7 \pm 3.7 \mathrm{~mL} / \mathrm{min}^{-1} \cdot \mathrm{kg}^{-1}$ and a ventilatory anaerobic threshold of $62( \pm 4) \%$ of the $\mathrm{VO}_{2} \max$. This high functional reserve can be associated with a process of natural selection and also with physiological adaptations induced by long training in a hostile environment ${ }^{62}$. Supporting the first hypothesis, a study showed that in Lhasa, Tibet $(3,658 \mathrm{~m})$, the newborns descending from the Tibetans had a higher arterial $\mathrm{SaO}_{2}$ at birth and during the first months of life than the descendents of the Chinese ${ }^{64}$. In regard to the second hypothesis, Curran et al ${ }^{22}$ compared within the same ethnic group Tibetans living at 4,400m and at 3,658m, through a cycloergometric test with direct oxygen consumption at $3,658 \mathrm{~m}$. The authors observed that the first group reached a higher load of exercise $(211+/-6$ versus $177+/-7$ watts, $\mathrm{p}<0.01)$ with a lower pulmonary ventilation $(127+/-5$ versus $149+/-5 \mathrm{~L} /$ $\operatorname{minBTPS}, \mathrm{p}<0.01)$.

The third group has been studied at moderate altitudes, 2,000 to 4,000m. Most of the people with heart disease can safely reach these altitudes, even though hypobaric hypoxia stimulates the autonomic nervous system and this response can be exacerbated by physical activity, therefore increasing the myocardial $\mathrm{VO}_{2}{ }^{23,65-67}$. During the first four days of exposure to high altitudes, the risks are higher ${ }^{21,63}$. A gradual ascent with limitation of the physical activity to a level lower than that performed at sea level, the improvement of physical conditioning before ascent and a strict control of pressure levels, in addition to a therapeutical scheme, minimize possible complications ${ }^{65,66}$. However, subgroups of patients with pulmonary hypertension, decompensated heart failure, unstable angina, recent acute myocardial infarction, noncontrolled severe atrial hypertension, severe pulmonary disease, homozygote sickle cell anemia, recurrent thromboembolic episodes, and patients with a severe anemia or reduction in $\mathrm{SaO}_{2}$ can be at high risk ${ }^{65,66}$. On the other hand, some individuals with the sickle cell trait have their first crisis of vascular occlusion during exercise at these altitudes. In competitions, they have the tolerance to exercise reduced, which until then had not been observed at sea level ${ }^{68}$.

Several sports activities are particularly dependent on high altitudes and have their peculiarities. A typical example is mountaineering.

Mountaineering - As a general rule, in long ascents at altitudes higher than $3,000 \mathrm{~m}$, the positive difference of the altitudes between two consecutive nights should not exceed $300 \mathrm{~m}$, and there should be two nights at the same altitude at every 3 days ${ }^{26}$.

Controlled studies have shown that the use of acetazolamide enhances the velocity of ascent by reducing the symptoms of AMS and improving physical performance ${ }^{46,47}$. Compared with individuals taking placebo, those using acetazolamide had a smaller weight loss, a smaller muscle mass loss and a greater tolerance for effort ${ }^{46}$.

To reduce the risks of dehydration caused by inspiration in a cold and dry environment, an abundant hydration with 3 to 5 liters of liquids per day is fundamental, as well as a diet rich in carbohydrates, which release more energy (5.0 $\left.\mathrm{kcal} / \mathrm{LO}_{2}\right)$ than lipids $\left(4.7 \mathrm{kcal} / \mathrm{LO}_{2}\right)^{69}$.

In regard to coca chewing, a common habit in the Andean countries, a study carried out at the Instituto Boliviano de Pesquisa by Spielvogel et al ${ }^{70}$ concluded that the beneficial effects of the herb were caused neither by an increase in the maximum capacity to exercise nor by its greater efficiency. Coca chewing increases the plasmatic concentration of free fatty acids and, therefore, can benefit prolonged submaximal exercisers.

Based on studies carried out in expeditions at high altitudes, above $7,500 \mathrm{~m}$, it has been observed that despite the extreme hypoxemia, the cardiac function is preserved with no electrocardiographic evidence of myocardial hypoxia ${ }^{11,71}$. Disorders of the central nervous system, however, are frequent and alterations in the motor coordination have been described persisting for more than 12 months ${ }^{71}$.

A relevant point is training athletes who are going to compete at moderate altitudes, when they come from regions close to the sea level. 
Athletic training - Limitations of performance in competitions at moderate altitudes were more carefully observed during the Olympic Games of 1968 in Mexican City, at $2,240 \mathrm{~m}$. Then, the athletes performing predominantly aerobic activities did not break records in activities such as long races. Good performance was observed only in activities of short duration, such as the 100-m races, in which the mobilization of sources of oxidative energy is small.

Acclimatization usually takes two weeks at moderate altitudes up to $2,300 \mathrm{~m}$. Beyond this altitude, to each additional ascent of $610 \mathrm{~m}$, one week should be added, up to the altitude of $4,572 \mathrm{~m}^{69}$, characterizing a gradual acclimatization considered more physiological and safer.

Our experience with soccer players, who acclimatized to compete at $3,600 \mathrm{~m}$, showed that the major complications resulting from the altitude such as headache, nausea, vomiting and reduction in performance were observed more often at the $3^{\text {rd }}$ and $7^{\text {th }}$ days of stay. These complications reappeared when the athletes moved to higher places, in a program of gradual acclimatization ${ }^{72}$.

One characteristic of the low threshold of sensitivity to hypobaric hypoxia that we observed was the elevation of the HR at rest, when waking up, 24 hours after the arrival at the altitude, in relation to the HR obtained at the wake up time at sea level. An $80 \%$ increase would indicate clinical complications at that altitude, requiring an individualized training ${ }^{73}$.

Training at altitude cannot be performed with the same intensity as that at sea level. Studies of university students revealed that the intensity of the training at $2,300 \mathrm{~m}$ would be $60 \%$ of the $\mathrm{VO}_{2}$ max reached at sea level, at $3,100 \mathrm{~m}$ it would be $56 \%$, and at $4,000 \mathrm{~m} 39 \%$ of the $\mathrm{VO}_{2} \mathrm{max}^{74}$. In practical terms, we believe there is certain difficulty in maintaining these levels of intensity, which certainly reach more elevated levels. Any symptom or clinical sign, however, can limit the athlete's physical activity.

It is believed that in prolonged sports competitions involving races and successive stops, such as soccer and basketball, the players may suffer little influence of the hypobaric hypoxia as a result of a reduced intensity training ${ }^{75}$. This reduction in the intensity of the physical training does not imply reduction in the tactical training, which should be maintained. This is especially important so that the players can get used to a change in the dynamics of the displacement of the ball consequent to the smaller atmospheric pressure.
We consider the training at progressively higher altitudes the best way to prepare a group of athletes to compete at altitudes higher than $2,600 \mathrm{~m}$. Our greatest experience was with the preparation of soccer players for competitions at $3,600 \mathrm{~m}$ in the city of $\mathrm{La} \mathrm{Paz}$, Bolivia $^{73}$.

The training started at low altitude and lasted 15 days. The workload was assessed considering the cardiorespiratory capacity obtained through ergospirometric tests in treadmill, with direct evaluation of the expired gases. The workload reached at the anaerobic threshold of the athlete was applied as base of training, because we considered it the most practical manner to prepare for the physical restrictions observed in hypobaric hypoxia. To exemplify, we briefly show the results of the ergospirometric evaluation of 15 soccer players for a competition at $3,600 \mathrm{~m}$ : age range: $26 \pm 2$ years; $\mathrm{VO}_{2}$ max: $61 \pm 3.7 \mathrm{~mL} / \mathrm{kg} / \mathrm{min}$; anaerobic threshold: $78 \pm 4.6 \%$ of the $\mathrm{VO}_{2}$ max; training intensity: $200 \pm 10 \mathrm{~m} /$ min; training HR: $143 \pm 12 \mathrm{bpm}^{73}$.

The effect of training was controlled during physical conditioning, applying the field tests (Guidelines ACSM) ${ }^{76}$. The best results were obtained with an initial training at $2,600 \mathrm{~m}$ during one week; at $2,900 \mathrm{~m}$ another week; and at 3,600 m during the week preceding the competition ${ }^{73}$.

We observed that after the period of acclimatization, the return to sea level is characterized by an improvement of the performance, consequent to training and, possibly, to the increase in the capacity of oxygen transportation. In the assessment of a group of 15 athletes, 16 days after a period of 2 weeks at 2,900 $\mathrm{m}$ (Quito, Ecuador) and a reassessment at $700 \mathrm{~m}$ (Poços de Caldas, Minas Gerais state, Brazil), which is a nonsignificant altitude, we obtained the following results of $\mathrm{VO}_{2}$ max in field tests ${ }^{76}$ : at $2,900 \mathrm{~m}, 50 \pm 2.8 \mathrm{~mL} / \mathrm{kg} / \mathrm{min}$, at $700 \mathrm{~m}, 57.42 \pm 3.6 \mathrm{~mL} / \mathrm{kg} / \mathrm{min}$, with significant differences ${ }^{72}$. Authors studying runners who underwent acclimatization at 2,300 and $4,000 \mathrm{~m}$, however, observed no significant improvement in the physical capacity after return from the altitude ${ }^{77}$.

Finally, we can conclude that competitions at moderate and high altitudes depend on adequate evaluation of the athlete, individual training regarding parameters obtained at sea level and at certain altitude, control of the body weight to establish a balance between caloric intake and physical activity, good hydration, gradual acclimatization, and perfect understanding between the technical team and athletes.

\section{References}

1. Barthelemy JC, Lacour JR, Roche F, et al. Elevated nocturnal blood pressure assessed by ambulatory automatic monitoring during a stay at high altitude. Eur J Appl Physiol 1995; 70: 258-62.

2. Rupwate RU, Chitaley M, Kamat SR. Cardiopulmonary functional changes in acute acclimatization to high altitude in mountaineers. Eur J Epidemiol 1990; 6: 266-72

3. Bernardi L, Passino C, Spadacini G, et al. Cardiovascular autonomic modulation and activity of carotid baroreceptors at altitude. Clin Sci (Colch) 1998; 95: 565-73.
4. Drinkwater BL, Kramar PO, Bedi JF, et al. Women at altitude: cardiovascular responses to hypoxia. Aviat Space Environ Med 1982; 53: 472-7.

5. Basu CK, Gautam RK, Sharma RP, et al. Metabolic responses during initial days of altitude acclimatization in the eastern Himalayas. Int J Biometeorol 1996; 39 : 133-8.

6. Korner PI. Circulation adaptation in hypoxia. Physiol Rev 1959; 39: 687-730.

7. Stenberg J, Ekblom B, Messin R. Hemodynamic response to work at simulated altitude, 4.000 m. J Appl Physiol 1966; 21: 1589-94. 
8. Passino C, Bernardi L, Spadacini G, et al. Autonomic regulation of heart rate and peripheral circulation: comparison of high altitude and sea level residents. Clin Sci(Colch) 1996; 91(suppl): 81-3.

9. Aigner A, Berghold F, Muss N. Investigations on the cardiovascular system at altitudes up to a height of 7.800 meters. Z Kardiol 1980; 69: 604-10.

10. Balke B. Cardiac performance at high altitude. Am J Cardiol 1964; 14: 796-810.

11. Malconian M, Rock $P$, Hultgren $H$, et al. The electrocardiogram at rest and exercise during a simulated ascent of Mt. Everest (Operation Everest II). Am J Cardiol 1990; 15: 1475-80.

12. D'Este D, Mantovan R, Martino A, et al. Blood pressure changes at rest and during effort in normotensive and hypertensive subjects in response to altitude acute hypoxia. G Ital Cardiol 1991; 21: 643-9.

13. Palatini P, Guzzardi G, Penzo M, et al. Effect of low and high altitude exposure on the blood pressure response to exercise. Cardiologia 1991; 36: 853-9.

14. Savonitto S, Cardellino G, Doveri G, et al. Effects of acute exposure to altitude $(3.460 \mathrm{~m})$ on blood pressure response to dynamic and isometric exercise in men with systemic hypertension. Am J Cardiol 1992; 70: 1493-7.

15. Asano K, Mazzeo RS, McCullough RE, et al. Relation of sympathetic activation to ventilation in man at 4.300 m altitude. Aviat Space Environ Med 1997; 682: 104-10.

16. Savard GK, Areskog NH, Saltin B. Cardiovascular response to exercise in humans following acclimatization to extreme altitude. Acta Physiol Scand 1995; 154: 499-509.

17. Sagawa S, Torii R, Nagaya K, et al. Carotid baroreflex control of heart rate during acute exposure to simulated altitudes of $3.800 \mathrm{~m}$ and $4.300 \mathrm{~m}$. Am J Physiol 1997; 273(pt 2): R1219-23.

18. Zaccaria M, bOREA PA, Opocher G, et al. Effects of high-altitude chronic hypoxia on platelet alpha 2-receptors in man. Eur J Clin Invest 1997; 27: 316-21.

19. Houston CS. Altitude Illness. The dangers of the heights and how to avoid them. Travel Medicine, Postgraduate Medicine 1983; 74: 231-48.

20. Forte VA, Leith DE, Muza SR, et al. Ventilatory capacities at sea level and high altitude. Aviat Space Environ Med 1997; 68: 488-93.

21. Malconian M, Hultgren $\mathrm{H}, \mathrm{Nitta} \mathrm{M}$, et al. The sleep electrocardiogram at extreme altitudes (Operation Everest II). Am J Cardiol 1990; 65: 1014-20.

22. Curran LS, Zhuang J, Droma T, et al. Superior exercise performance in lifelong Tibetan residents of $4.400 \mathrm{~m}$ compared with Tibetan residents of $3.658 \mathrm{~m}$. Am J Phys Anthropol 1999; 105: 21-31.

23. Levine BD, Zuckerman JH, deFilippi CR. Effect of high-altitude exposure in the elderly: the Tenth Mountain Division study. Circulation 1997; 96: 1224-32.

24. Richalet JP, Rathat C. Pathologie et Altitude. Paris: Masson, 1991.

25. Davila-Roman VG, Guest TM, Tuteur PG, et al. Transient right but not left ventricular dysfunction after strenuous exercise at high altitude. J Am Coll Cardiol 1997; 30: 468-73.

26. A'Court CHD, Stables RH, Travis S. Doctor on a mountaineering expedition. $\mathrm{Br}$ Med J 1995; 310: 1248-52.

27. Cummings P, Lysgaard M. Cardiac arrhythmia at high altitude. West J Med 1981; 135: 66-8.

28. Roberts AC, Reeves JT, Butterfield GE, et al. Altitude and beta-blockade augment glucose utilization during submaximal exercise. J Appl Physiol 1996; 80: 605-15.

29. McClelland GB, Hochachka PW, Weber JM. Carbohydrate utilization during exercise after high-altitude acclimation: a new perspective. Proc Natl Acad Sci USA 1998; 95: 10288-93.

30. Tunny TJ, van Gelder J, Gordon RD, et al. Effects of altitude on atrial natriuretic peptide: the Bicentennial Mount Everest Expedition. Clin Exp Pharmacol Physiol 1989; 16: 287-91.

31. Zaccaria M, Rocco S, Noventa D, et al. Sodium regulating hormones at high altitude: basal and post-exercise levels. J Clin Endocrinol Metab 1998; 83: 570-4.

32. Morganti A, Giussani M, Sala C, et al. Effects of exposure to high altitude on plasma endothelin-1 levels in normal subjects. J Hypertens 1995; 13: 859-65.

33. Droma Y, Hayano T, Takabayashi y, et al. Endothelin- 1 and interleukin- 8 in high altitude pulmonary edema. Eur Respir J 1996; 9: 1947-9.

34. Klausen T, Poulsen TD, Fogh-Andersen N, et al. Diurnal variations of serum erythropoietin at sea level and altitude. Eur J appl Physiol 1996; 72: 297-302.

35. Gunga HC, Rocker L, Behn C, et al. Shift working in the Chilean Andes ( $>3.600$ $\mathrm{m})$ and its influence on erythropoietin and the low-pressure system. J Appl Physiol 1996; 81: 846-52.

36. Boning D, Maassen N, Jochum F, et al. After-effects of a high altitude expedition on blood. Int J Sports Med 1997; 18: 179-85.

37. Asano M, Kaneoka K, Nomura T, et al. Increase in serum vascular endothelial growth factor levels during altitude training. Acta Physiol Scand 1998; 162: 455-9.

38. Richalet JP, León-Velarde F. Fisiopatología de la altitud. Arch Med Deporte 1997; 60: 271-6.

39. Beidleman BA, Muza SR, Rock PB, et al. Exercise responses after altitude acclimatization are retained during reintroduction to altitude. Med Sci Sports Exerc 1997; 29: 1588-95.

40. Sawka MN, Young AJ, Rock PB, et al. Altitude acclimatization and blood volume: effects of exogenous erythrocyte volume expansion. J Appl Physiol 1996; 81: 636-42.

41. Chen QH, Ge RL, Wang XZ, et al. Exercise performance of Tibetans and adolescents at altitudes of 3.417 and 4.300m. J Appl Physiol 1997; 83: 661-7.

42. Boutellier U, Deriaz O, di Prampero PE, et al. Aerobic performance at altitude: effects of acclimatization and hematocrit with reference to training. Int J Sports Med 1990; 11(suppl 1): S21-26.

43. West JB. Rate of ventilatory acclimatization to extreme altitude. Respir Physiol 1988; 74: 323-33.

44. Harris MD, Terrio J, Miser WF, et al. High-altitude medicine. Am Fam Physician 1998; 57: 1904-14, 1924-6.

45. Bartsch P. High altitude pulmonary edema. Respiration 1997; 64: 435-43.

46. Bradwell AR, Coote JH, Milles JJ, et al and Birmingham Medical Research Expeditionary Society - Effect of acetazolamide on exercise performance and muscle mass at high altitude. Lancet 1986: 1001-5.

47. Birmingham Medical Research Expeditionary Society Mountain Sickness Study Group - Acetazolamide in control of acute mountain sickness. Lancet 1981: 180-3.

48. Arnett FC. High-Altitude Pulmonary edema. An immunogenetically mediated disease? Circulation 1998; 97: 1111-13.

49. Hanaoka M, Kubo K, Yamazaki Y, et al. Association of high-altitude pulmonary edema with the major histocompatibility complex. Circulation 1998; 97: 1124-28.

50. Serrano Duenas M. High-altitude pulmonary edema. Study of 21 cases. Med Clin(Barc) 1998; 110: 446-9.

51. Eldridge MW, Podolsky A, Richardson RS, et al. Pulmonary hemodynamic response to exercise in subjects with prior high-altitude pulmonary edema. $\mathrm{J}$ Appl Physiol 1996; 81: 911-21.

52. Kubo K, Hanaoka M, Hayano T, et al. Inflammatory cytokines in BAL fluid and pulmonary hemodynamics in high-altitude pulmonary edema. Resp Physiol 1998; 111: 301-10.

53. Reeves JT, Schoene RB. When lungs on mountains leak. Studying pulmonary edema at high altitudes. N Engl J Med 1991; 325: 1306-7.

54. Oelz O,Ritter M, Jenni R, et al. Nifedipine for high-altitude pulmonary oedema. Lancet 1989; 2: 1241-44.

55. Bärtsch $P$, Maggiorini M, Ritter M, et al. Prevention of high-altitude pulmonary edema by nifedipine. N Engl J Med 1991; 325: 1284-9.

56. Anand IS, Prasad BAK, Chugh SS, et al. Effects of inhaled nitric oxide and oxygen in high-altitude pulmonary edema. Circulation 1998; 98: 2441-45.

57. Naeije R. Pulmonary circulation at high altitude. Respiration 1997; 64: 429-34

58. Schoene RB, Swenson ER, Pizzo CJ, et al. The lung at high altitude: bronchoalveolar lavage in acute mountain sickness and pulmonary edema. J Appl Physiol 1988; 64: 2605-13.

59. West JB, Colice GL, Lee YJ, et al. Pathogenesis of high-altitude pulmonary oedema: direct evidence of stress failure of pulmonary capillaries. Eur Respir J 1995; 8: 523-9.

60. Hultgren HN. High-altitude pulmonary edema: hemodynamic aspects. Int J Sports Med 1997; 18: 20-5.

61. Steinacker JM, Tobias P, Menold E, et al. Lung diffusing capacity and exercise in subjects with previous high-altitude pulmonary oedema. Eur Respir J 1998; 11: 643-50.

62. Garrido E, Rodas G, Javierre C, et al. Cardiorespiratory response to exercise in elite Sherpa climbers transferred to sea level. Med Sci Sports Exerc 1997; 29: 937-2.

63. Kofstad J. Oxygen uptake and transport in the human organism on the summit of Mt. Everest. Scand J Clin Lab Invest Suppl 1990; 203: 223-6.

64. Niermeyer S, Yang P, Shamnina, et al. Arterial oxygen saturation in Tibetan and Han infants born in Lhasa, Tibet. N Engl J Med 1995; 333: 1248-52.

65. Allemann Y, Saner H, Meier B. High-altitude stay and air travel in coronary heart disease. Schweiz Med Wochenschr 1998; 128: 671-8.

66. Squires RW. Moderate Altitude exposure and the cardiac patient. J Cardiopulmonary Rehab 1985; 5: 421-6.

67. Roach RC, Houston CS, Honigman B, et al. How well do older persons tolerate moderate altitude? West J Med 1995; 162: 32-6.

68. Thiriet P, Le Hesran JY, Wouassi D, et al. Sickle cell trait performance in a prolonged race at high altitude. Med Sci Sports Exerc 1994; 26: 914-18.

69. Mc Ardle WD, Katla FI, Katch VL. Exercise Physiology. Energy, Nutrition and Human Performance. Philadelphia: Lea \& Febiger, 1981

70. Spielvogel $\mathrm{H}$, Caceres E, Koubi $\mathrm{H}$, et al. Effects of coca chewing on metabolic and hormonal changes during graded incremental exercise to maximum. J Appl Physiol 1996; 80: 643-9.

71. West JB. Tolerance to severe hypoxia: lessons from Mt. Everest. Acta Anaesthesiol Scand Suppl 1990; 94: 18-23. 
72. Vivacqua RVC. Aclimatação cardio-respiratória de atletas à altitude. Arq Bras Cardiol 1985; 45: 287-92.

73. Vivacqua R, Hespanha R. Atletas e Competições em Altitude. In: Vivacqua R, Hespanha R - Ergometria e Reabilitação em Cardiologia. Rio de Janeiro: MEDSi, 1992: 344-59.

74. Viana AR, Guedes DP, Leite PF, et al. Futebol. Bases científicas do treinamento físico. Sprint, 1987.
75. Proceedings of the International Symposium on the Effects of Altitude on Physical Performance: The Athletic Institute, Chicago, 1987. In: Goddar R, (ed ) - Training for Competition at Moderate Altitude. Adv Cardiol 1970; 5: 1-10.

76. American College of Sports Medicine - Guidelines for Exercise Testing and Exercise Prescription. Philadelphia: Lea \& Fabinger, 1986.

77. Sutton JR, Jones N, Houston CS. Hypoxia: Man at Altitude. New York: Thieme Stratton, 1982. 